\title{
Selective Cannabinoid 2 Receptor Stimulation Reduces Tubular Epithelial Cell Damage after Renal Ischemia-Reperfusion Injury ${ }^{\mathbb{S}}$
}

\author{
Jeffrey D. Pressly, Suni M. Mustafa, Ammaar H. Abidi, Sahar Alghamdi, Pankaj Pandey, \\ Kuldeep K. Roy, Robert J. Doerksen, Bob M. Moore, Jr., and Frank Park \\ Department of Pharmaceutical Sciences, College of Pharmacy, University of Tennessee Health Science Center, Memphis, \\ Tennessee (J.D.P., S.M.M., A.A., S.A., B.M.M., F.P.); Division of Medicinal Chemistry, Department of Biomolecular Sciences \\ (P.P., K.K.R., R.J.D.) and Research Institute of Pharmaceutical Sciences (R.J.D.), School of Pharmacy, University of Mississippi, \\ University, Mississippi; and National Institute of Pharmaceutical Education and Research, Jadavpur, Kolkata, West Bengal, India \\ (K.K.R.)
}

Received October 4, 2017; accepted November 22, 2017

\begin{abstract}
Ischemia-reperfusion injury (IRI) is a common cause of acute kidney injury (AKI), which is an increasing problem in the clinic and has been associated with elevated rates of mortality. Therapies to treat $\mathrm{AKI}$ are currently not available, so identification of new targets that can be modulated to ameliorate renal damage upon diagnosis of $\mathrm{AKI}$ is essential. In this study, a novel cannabinoid receptor 2 (CB2) agonist, SMM-295 [3'-methyl-4-(2-(thiophen-2-yl)propan2-yl)biphenyl-2,6-diol], was designed, synthesized, and tested in vitro and in silico. Molecular docking of SMM-295 into a CB2 active-state homology model showed that SMM-295 interacts well with key amino acids to stabilize the active state. In human embryonic kidney 293 cells, SMM-295 was capable of reducing cAMP production with 66-fold selectivity for CB2 versus cannabinoid receptor 1 and dose-dependently increased mitogenactivated protein kinase and Akt phosphorylation. In vivo testing
\end{abstract}

of the CB2 agonist was performed using a mouse model of bilateral IRI, which is a common model to mimic human $\mathrm{AKI}$, where SMM-295 was immediately administered upon reperfusion of the kidneys after the ischemia episode. Histologic damage assessment 48 hours after reperfusion demonstrated reduced tubular damage in the presence of SMM-295. This was consistent with reduced plasma markers of renal dysfunction (i.e., creatinine and neutrophil gelatinase-associated lipocalin) in SMM-295-treated mice. Mechanistically, kidneys treated with SMM-295 were shown to have elevated activation of Akt with reduced terminal deoxynucleotidyl transferase-mediated digoxigenin-deoxyuridine nickend labeling (TUNEL)-positive cells compared with vehicle-treated kidneys after IRI. These data suggest that selective CB2 receptor activation could be a potential therapeutic target in the treatment of AKI.
This work was partially funded by the University of Tennessee Health Science Center [institutional funds (to F.P.)], the National Institutes of Health National Institute of Diabetes and Digestive and Kidney Diseases [Grants R01-DK090123 (to F.P.), and the National Institutes of Health National Institute of General Medical Sciences [Grants P20-GM104932 and R15GM119061 (to R.J.D.)]. Supercomputer support from the National Science Foundation [Grant MRI1338056] and the Mississippi Center for Supercomputer Research [both to (R.J.D.)] is acknowledged. This investigation was conducted in part in a facility constructed with support from the National Institutes of Health Research Facilities Improvements Program [Grant C06RR14503 (to R.J.D.)].

https://doi.org/10.1124/jpet.117.245522.

S This article has supplemental material available at jpet.aspetjournals.org.

\section{Introduction}

Acute kidney injury (AKI) has clinically become an increasing problem for patients of all ages and has been linked to an elevated risk of mortality (Chertow et al., 2005; Wang et al., 2012). The majority of the patients that develop AKI are in a prerenal state, defined by organ hypoperfusion associated with sepsis, fluid depletion, pharmacological reductions in blood pressure, and vessel occlusion (Macedo and Mehta, 2009; Basile et al., 2012). AKI is an important risk factor in the progression toward chronic kidney disease, which can also be a reciprocal risk factor in potentiating the onset of AKI

ABBREVIATIONS: AKI, acute kidney injury; AM-1241, 1-(methylpiperidin-2-ylmethyl)-3-(2-iodo-5-nitrobenzoyl)indole; AR, androgen receptor; AUC, area under the concentration-time curve; CB1, cannabinoid receptor 1; CB2, cannabinoid receptor 2; CC3, cleaved caspase 3; CNG, cyclic nucleotide gated; CP 55,940, 2-[(1R,2R,5R)-5-hydroxy-2-(3-hydroxypropyl) cyclohexyl]-5-(2-methyloctan-2-yl)phenol; DMSO, dimethylsulfoxide; GPCR, G protein-coupled receptor; HEK, human embryonic kidney; HU-308, (1R,2R,5R)-2-[2,6-Dimethoxy-4-(2-methyloctan-2-yl)phenyl]-7,7dimethyl-4-bicyclo[3.1.1]hept-3-enyl]methanol; HU-910, [((1S,4R)-2-(2,6-dimethoxy-4-(2-methyloctan-2-yl)phenyl)-7,7-dimethylbicyclo[2.2.1]hept-2en-1-yl)methanol; IRI, ischemia-reperfusion injury; JWH-133, (6aR,10aR)-3-(1,1-dimethylbutyl)-6a,7,10,10a-tetrahydro-6,6,9-trimethyl-6Hdibenzo[b,d]pyran; LC, liquid chromatography; LEl-101, 3-cyclopropyl-1-[[4-[6-[(1,1-dioxido-4-thiomorpholinyl)methyl]-5-fluoro-2-pyridinyl]phenyl]methyl]-2,4-imidazolidinedione; MAPK, mitogen-activated protein kinase; MS/MS, tandem mass spectrometry; NGAL, neutrophil gelatinase-associated lipocalin; P-gp, P-glycoprotein; P450, cytochrome P450; PBS, phosphate-buffered saline; PCNA, proliferating cell nuclear antigen; PDB, Protein Data Bank; RED, rapid equilibrium dialysis; Ro 20-1724, 4-(3-butoxy-4-methoxyphenyl)methyl-2-imidazolidone; SMM-189, [4(3,5-dichlorophenyl)-35-dihydroxy-phenyl]-phenyl-methanone; SMM-295, 3'-methyl-4-(2-(thiophen-2-yl)propan-2-yl)biphenyl-2,6-diol; $t_{\text {max }}$, time to reach the maximum concentration; TUNEL, terminal deoxynucleotidyl transferase-mediated digoxigenin-deoxyuridine nick-end labeling; WIN 55,212-2, (R)-(+)-[2,3-dihydro-5-methyl-3-(4-morpholinylmethyl)pyrrolo[1,2,3-de]-1,4-benzoxazin-6-yl]-1-naphthalenylmethanone. 
(Chawla et al., 2014; Heung and Chawla, 2014). At present, there remains a lack of adequate therapeutic approaches to treat patients after an episode of AKI. Even though there is increased knowledge regarding the mechanisms involved in the onset of AKI and the subsequent recovery of damaged renal cells, particularly tubular epithelial cells (Bonventre and Yang, 2011; Yang et al., 2011; Basile et al., 2012), further investigations are needed to expand on our current level of understanding to increase the likelihood of developing new therapeutic targets.

The role of the endocannabinoid system in the kidney after activation of its cognate $\mathrm{G}$ protein-coupled receptors (GPCRs), cannabinoid receptors 1 and 2 (CB1 and CB2, respectively), is continuing to emerge as a crucial response system after injury stimuli to the kidney. CB1 and CB2 activation can exert a diverse array of biologic functions due to a combination of factors, which includes their ability to interact with several heterotrimeric G-protein $\alpha$ subunits, including $\mathrm{G} \alpha \mathrm{i}, \mathrm{G} \alpha \mathrm{s}$, and G $\alpha \mathrm{q} / 11$ (Hryciw and McAinch, 2016), and their distribution within the distinct cell types in the kidney. The CB1 receptors are expressed in high abundance with a fairly broad localization pattern, which includes all segments of the nephron and vasculature (Hryciw and McAinch, 2016). On the other hand, the CB2 receptor has been primarily detected in the renal cortex, specifically in mesangial cells and podocytes in the glomerulus (Deutsch et al., 1997; Barutta et al., 2011), and in proximal tubular epithelial cells (Jenkin et al., 2010, 2013, 2016). The CB2 receptor is an attractive pharmaceutical target owing to the lack of psychotropic effects associated with CB1 receptor activation (Mukhopadhyay et al., 2010a). Selective activation of the CB2 receptor has been shown to protect renal architecture and nephron function by mitigating the nephropathic effects associated with diabetes (Mukhopadhyay et al., 2010b; Zoja et al., 2016) or dietinduced obesity (Jenkin et al., 2016) in rodent models of chronic kidney injury. Diabetic nephropathy was attenuated after treatment with the natural product CB2 receptor agonist $\beta$-caryophyllene (Horváth et al., 2012) or a small molecule analog functioning as a CB2 agonist (Mukhopadhyay et al., 2010b). Similarly, CB2 receptor activation in rodents with diet-induced obesity ameliorated their progression toward renal dysfunction, as determined by urinary protein and sodium excretion rates (Jenkin et al., 2016). Conversely, CB2 receptor antagonists reduced renal function, as measured by creatinine clearance, which suggests that renal failure was exacerbated (Jenkin et al., 2016). These data demonstrate the potential clinical benefit of CB2 receptor agonists to treat chronic forms of kidney injury, but further investigations are needed to determine the utility of harnessing the CB2 receptor system after AKI.

To address this issue, our scientific group developed a small molecule agonist, SMM-295 [3'-methyl-4-(2-(thiophen-2-yl)propan-2-yl)biphenyl-2,6-diol], for investigation of the CB2 receptor as a potential therapeutic target in the prevention of tubular epithelial cell damage after AKI. Our molecular modeling data demonstrated that SMM-295 has tight interactions with the active state of the CB2 receptor. To test this compound, we used a mouse model of renal bilateral ischemiareperfusion injury (IRI), which is a common experimental model to study AKI, to demonstrate the considerable beneficial effects of SMM-295. Our findings substantiate that further investigation into selective activation of the CB2 receptor has merit and may provide a new target for therapy in the treatment of AKI.

\section{Materials and Methods}

\section{Reagents}

G418 was purchased from KSE Scientific (Durham, NC). Puromycin, Dulbecco's modified Eagle's medium, penicillin/streptomycin, gentamicin, Dulbecco's phosphate-buffered saline (PBS), Hank's buffer, HEPES, EDTA, Tris base, sucrose, $\mathrm{MgCl}_{2}$, Millipore filter plates and punch kits, Eco-Lite scintillation cocktail, and poly(Llysine)-coated 96-well plates were purchased from Thermo Fisher Scientific (Waltham, MA). Ambisome and fetal bovine serum were purchased from Atlanta Biologicals (Flowery Branch, GA). Ro 20-1724, acetonitrile, dimethylsulfoxide (DMSO), lipopolysaccharide, polyethyleneamine, and fatty acid-free bovine serum albumin were purchased from Sigma-Aldrich (St. Louis, MO). Antibodies against proliferating cell nuclear antigen (PCNA) were purchased from Cell Signaling Technologies (Danvers, MA). High bind plates (L15XB-3) and anti-rat (R32AA-5) and anti-rabbit (R32AB-1) SULFO-TAG antibodies were purchased from Meso-Scale Discovery (Gaithersburg, MD). ACTOne Membrane Potential Dye was purchased from Codex BioSolutions (Gaithersburg, MD). Forskolin was purchased from Tocris (Bristol, UK).

\section{Chemical Synthesis of SMM-295}

The chemical design and synthesis of SMM-295 (Fig. 1A) is detailed in Supplemental Scheme 1.

\section{Molecular Modeling of SMM-295}

A collection of active-state models of CB2 was constructed using a multitemplate approach with the following X-ray crystal structures of active states of GPCRs: 1) $\beta_{2}$-androgen receptor (AR)-Gs complex [Protein Data Bank (PDB) identifier 3SN6] (Rasmussen et al., 2011b), 2 ) nanobody stabilized $\beta_{2}$-AR-agonist complex [PDB identifier 3P0G] (Rasmussen et al., 2011a), 3) $\beta_{1}$-AR-agonist complex [PDB identifier 2Y02] (Warne et al., 2011), and 4) bovine rhodopsin [PDB identifier: 3PQR] (Choe et al., 2011). Of the 100 generated models, an optimal model was chosen according to molpdf and DOPE (Discrete Optimized Protein Energy) scores (Sali and Blundell, 1993). Quality assessment of the models was performed by assessing their Ramachandran plot. To verify docking into the appropriate active site, well-known tight-binding CB2 agonists, including HU-308 [(1R,2R,5R)-2-[2,6-Dimethoxy-4-(2-methyloctan-2-yl)phenyl]-7,7-dimethyl-4-bicyclo[3.1.1]hept-3-enyl]methanol], WIN 55,212-2 [(R)-(+)-[2,3-dihydro-5-methyl-3-(4-morpholinylmethyl) pyrrolo[1,2,3-de]-1,4-benzoxazin-6-yl]-1-naphthalenylmethanone], CP 55,940 2-[(1R,2R,5R)-5-hydroxy-2-(3-hydroxypropyl) cyclohexyl]-5-(2methyloctan-2-yl)phenol], and JWH-133 [(6aR,10aR)-3-(1,1-dimethylbutyl)-6a,7,10,10a-tetrahydro-6,6,9-trimethyl-6H-dibenzo[b,d]pyran], were used for validation of the CB2 models. The best CB2 activestate model was used for a molecular dynamics simulation with $\mathrm{CP}$ 55,940 in the active site using NAMD software (version 2.9, Linus x86-64 multicore-cuda; University of Illinois at Urbana-Champaign Beckman Institute for Advanced Science and Technology, Urbana, IL). During 140-200 nanoseconds of simulation, both protein and ligand maintained a significantly stable pose and details of which residues of CB2 interacted with CP 55,940 matched well with experimental mutagenesis data. Details of the preparation of the CB2 receptor models will be reported elsewhere (R.J. Doerksen et al., manuscript in preparation). The final frame of the molecular dynamics simulation was selected as the starting point for the present calculations. SMM-295 was sketched in Maestro (Schrödinger release 2016-3; Schrödinger, LLC, New York, NY) and was further energy minimized using LigPrep (Zhang et al., 2011) at physiologic $\mathrm{pH}$ 7.4. The docking site was chosen to be the centroid of residues Lys109, Ser112, Phe117, Trp194, Trp258, Lys278, and Ser285 (Hurst et al., 2010; Reggio, 2010; Zhang et al., 2011) of the 
A SMM-295<smiles>Cc1cccc(-c2c(O)cc(C(C)(C)c3cccs3)cc2O)c1</smiles>

B

\section{SMM-295} (ng/mL)

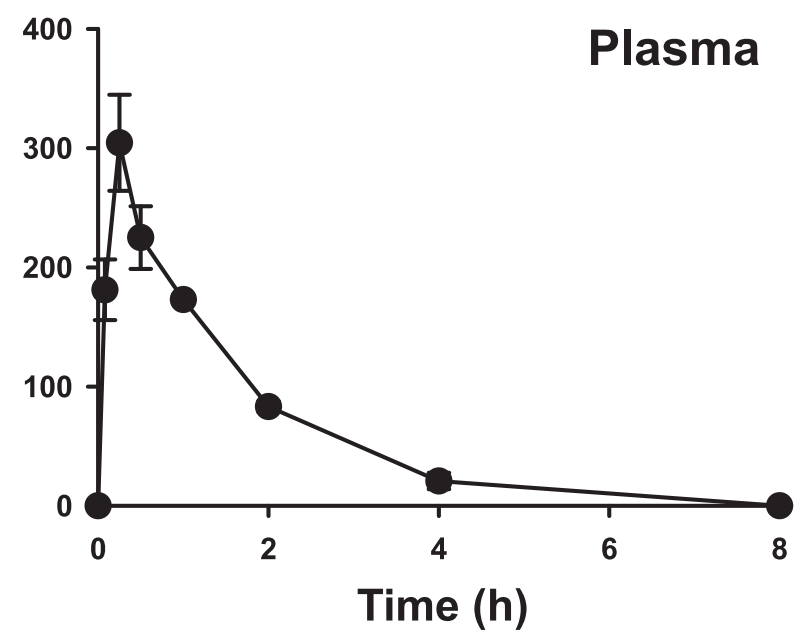

Fig. 1. Chemical structure and in vivo pharmacokinetics of SMM-295. (A) The chemical structure of SMM-295 is shown. (B and C) C57BL/6J mice were administered $6 \mathrm{mg} / \mathrm{kg}$ into the intraperitoneal space and blood and kidneys were harvested at the appropriate time points shown in the graph. Plasma (B) and kidney tissue (C) levels of SMM-295 were measured by LC-MS/MS, and the half-life was calculated and graphed. $n=3$ mice/time point.

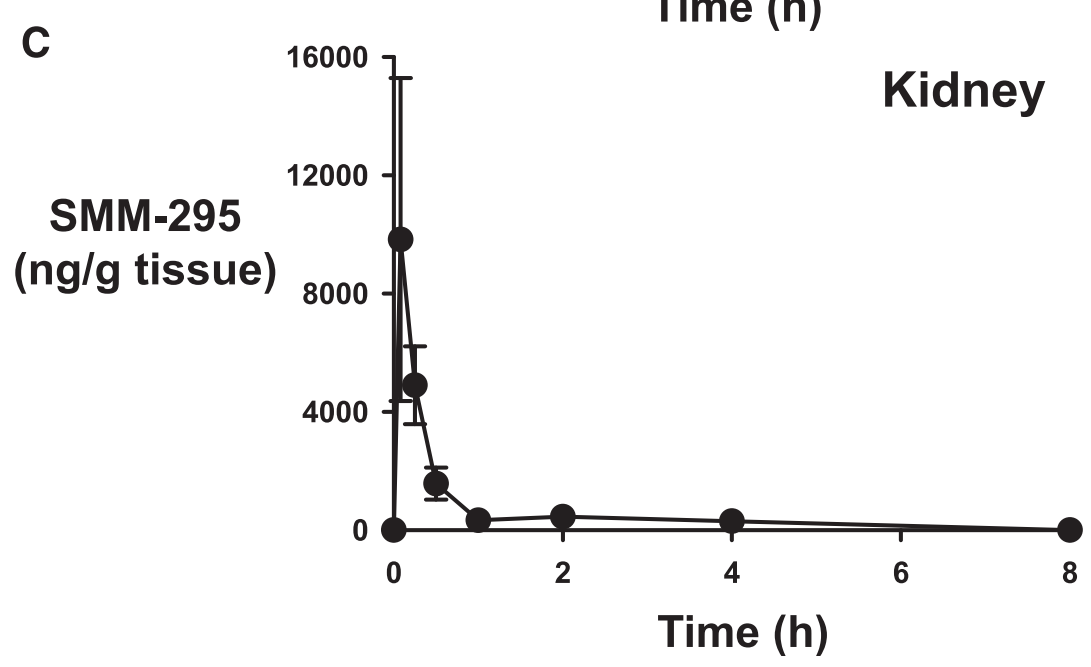

CB2 model. We used the Induced Fit Docking (IFD) protocol (Schrödinger Suite 2016-3 Induced Fit Docking protocol; Glide, Schrödinger, LLC, New York, NY, 2016; Prime, Schrödinger, LLC, New York, NY, 2016) " (Sherman et al., 2006) to allow side chains within $5 \AA$ A of the docked ligand to be adjusted for optimization of the binding mode and the docking score. Induced fit docking was used with extra-precision mode (Friesner et al., 2006) and the OPLS3 [Optimized Potentials for Liquid Simulations 3] (Harder et al., 2016) force field for final positioning of the ligands and for scoring the docked poses. After docking, the binding free energies of the complexes (CB2:SMM-295) were calculated using the Prime Molecular Mechanics -Generalized Born Surface Area (Prime MM-GBSA) module of the Schrödinger suite (Sherman et al., 2006).

\section{Receptor Binding and Activity}

Membrane proteins were isolated using binding buffer, as previously described (Presley et al., 2015b). Prior to starting the assay, filter plates were prepared by incubation with $0.05 \%(\mathrm{w} / \mathrm{v})$ polyethyleneamine mixed in deionized water for 60 minutes at room temperature. Afterward, plates were filtered and washed five additional times with deionized water using a vacuum manifold. In each well, $10 \mu \mathrm{g}$ membrane protein was added in the presence of $\left[{ }^{3} \mathrm{H}\right]-\mathrm{CP} 55,940$ (1 nM final concentration) with or without test ligands such as SMM295 (concentration range from $1 \mathrm{nM}$ to $10 \mu \mathrm{M}$ ). The samples were incubated at $30^{\circ} \mathrm{C}$ for 90 minutes and then washed nine times using binding buffer. At the end of the final wash, the plate backing was removed and vacuum dried and individual filters were collected using punch tips into scintillation vials containing Eco-Lite scintillation solution $(5 \mathrm{ml})$. Vials were incubated overnight and were analyzed the following day using Tri-Carb 2810TR Liquid Scintillation Analyzer (PerkinElmer, Waltham, MA), with a dwell time of 3 minutes. All binding studies were performed with a minimum of six biologic replicates, and $K_{\mathrm{d}}$ and $B_{\max }$ were measured.

\section{ACTOne Functional Assay}

Human embryonic kidney (HEK)-cyclic nucleotide gated (CNG), HEK-CNG+CB1, and HEK-CNG+CB2 cells were obtained from Codex BioSolutions. The ACTOne functional assay was performed as described by Presley et al. (2015b). In brief, $5 \times 10^{4}$ cells were plated 
into clear poly-(D-lysine)-coated 96-well plates using Dulbecco's modified Eagle's medium containing $10 \%$ fetal bovine serum and $1 \%$ penicillin/streptomycin. The following day, SMM-295 or CP 55,940 was evaluated at final concentrations from $5 \mu \mathrm{M}$ down to $500 \mathrm{pM}$ in the presence of Ro 20-1724 $(25 \mu \mathrm{M})$ and/or forskolin $(0.8 \mu \mathrm{M})$ in Dulbecco's PBS with $2.5 \%$ (v/v) DMSO. At this point, the plates were read using a BioTek plate reader (excitation, $540 \mathrm{~nm}$; emission, $590 \mathrm{~nm}$; BioTek Instruments, Winooski, VT) at 50 minutes. At least six biologic replicates were performed for each data set.

\section{Physicochemical Property Assessment}

$\log \mathrm{P}$ was calculated using $\mathrm{S}+\log \mathrm{P}$, an artificial neural network ensemble method available in ADMET Predictor 8.1 software (Simulations Plus, Lancaster, CA) (Tetko and Poda, 2007). Solubility was determined at $\mathrm{pH} 7.4$ using a miniaturized shake-flask method (Glomme et al., 2005). Drug suspension was shaken for 24 hours in a buffer solution at room temperature and centrifuged and the supernatant analyzed by liquid chromatography (LC)-tandem mass spectrometry (MS/MS).

\section{Drug Permeability Assay}

Bidirectional drug permeability for SMM-295 (5 $\mu \mathrm{M})$ was tested using the Caco-2 human epithelial cell line as previously described (Himanshu et al., 2013). As a positive control for P-glycoprotein (P-gp) efflux, loperamide $(5 \mu \mathrm{M})$ was used in the assay. Verapamil $(100 \mu \mathrm{M})$ was used as an inhibitor for P-gp transport activity. All data are shown as $10^{-6} \mathrm{~cm} / \mathrm{s}$

\section{Plasma Protein Binding by SMM-295}

Rapid equilibrium dialysis (RED) was performed using a commercial plate-based RED device. SMM-295 was diluted to a final concentration of $5 \mu \mathrm{M}$ in triplicate using mouse and human plasma. As a control, warfarin was diluted to $5 \mu \mathrm{M}$ using mouse and human plasma, and PBS (pH 7.4) was added to the buffer chamber. After the RED device was sealed with an adhesive film, dialysis was performed in an incubator at $37^{\circ} \mathrm{C}$ with shaking at $100 \mathrm{rpm}$ for 4 hours. Aliquots of the buffer and the plasma were measured at specific times with a calibration curve by LC-MS/MS to determine the concentration of free and bound test compound by LC-MS/MS analysis. The calculation of the peak area ratios between the analyte versus the internal standard was used to determine the fraction of compound bound to plasma proteins.

\section{Cytochrome P450 Metabolism Assay}

The in vitro stability of SMM-295 was assessed in duplicate using purified cytochrome P450 (P450) enzymes and measuring the disappearance of the native compound over an incubation period of 60 minutes. The various $\mathrm{P} 450$ proteins $(50 \mathrm{pmol} / \mathrm{ml})$ and their positive control drugs (in parentheses; $1 \mu \mathrm{M}$ ) tested in our assay are as follows: CYP1A2 (phenacetin), CYP3A4 (terfenadine), CYP2C9 (diclofenac), CYP2C19 (lansoprazole), and CYP2D6 (propranolol). SMM-295 $(1 \mu \mathrm{M})$ was added to each of the $\mathrm{P} 450$ enzymes, and the samples were placed in a 96 -well plate that was preincubated at $37^{\circ} \mathrm{C}$. NADPH was added to a final concentration of $1 \mathrm{mM}$ to initiate the reaction, and all reactions were terminated using ice-cold acetonitrile containing an internal standard at $0,5,15,30$, and 60 minutes. The plates were centrifuged at $4000 \mathrm{rpm}$ for 15 minutes, and an aliquot from each sample was analyzed by LC-MS/MS to determine the percentage change in the native versus metabolized compounds and the calculation of the compound half-life.

\section{Human Ether-a-Go-Go-Related Gene Assay}

The potential inhibitory effect by SMM-295 (1 and $10 \mu \mathrm{M})$ on the human ether-a-go-go-related gene (hERG) channel was evaluated using the predictor hERG fluorescence polarization assay kit as per the manufacturer's instructions (Life Technologies, Carlsbad, CA).

\section{In Vivo Pharmacokinetic Studies}

Animal studies were performed by SAI Life Sciences Ltd. (Hyderabad, India) using an institutional animal ethics committee protocol (number FB-15-103). Twenty-seven male C57BL/6J mice (aged 8-12 weeks; 25-35 g) were obtained from ACTREC (Maharashtra, India) and maintained in a temperature- and humidity-controlled environment under 12-hour light/dark cycles. All mice were allowed ad libitum access to food (Envigo Research Private Ltd., Hyderabad, India) and water.

The mice were administered SMM-295 (6 mg/kg i.p.), which was formulated in $5 \%(\mathrm{v} / \mathrm{v})$ 200-proof ethanol, $5 \%(\mathrm{v} / \mathrm{v})$ Cremophor ELP (BASF, Germany), and 90\% normal saline. At each time point (0.08, $0.25,0.5,1,2,4,8,12$, and 24 hours), three mice were euthanized to collect blood and kidney samples for measurement of SMM-295. Plasma was isolated from the collected blood by centrifugation, and the kidneys were immediately homogenized using ice-cold PBS $(\mathrm{pH}$ 7.4). The plasma and kidney homogenates were stored at $-70^{\circ} \mathrm{C}$ until analysis by fit-for-purpose validation by LC-MS/MS to obtain the concentration-time data for SMM-295. Subsequently, the plasma concentration-time data were used to calculate other pharmacokinetic variables using the noncompartmental analysis module in Phoenix WinNonlin software (version 6.3; Certara, Princeton, NJ). Maximum concentration $\left(C_{\max }\right)$ and time to reach the maximum concentration $\left(t_{\max }\right)$ were the observed values. The areas under the concentration-time curve ( $\mathrm{AUC}_{\text {last }}$ and $\mathrm{AUC}_{\text {inf }}$ ) were calculated using the linear trapezoidal rule. The terminal elimination rate constant $\left(k_{\mathrm{e}}\right)$ was determined by regression analysis of the linear terminal portion of the log plasma concentration-time curve.

\section{LC-MS/MS Assay of SMM-295}

Plasma and kidney homogenates in ice-cold PBS ( $\mathrm{pH}$ 7.4) were isolated by centrifugation, and protein extraction was achieved using a $4: 1$ (acetonitrile/sample) ratio. As an internal control, glipizide (500 ng/ml) was added to each sample except for the blank control. Samples were vortexed and centrifuged for 10 minutes at $4000 \mathrm{rpm}$ at $4^{\circ} \mathrm{C}$. After centrifugation, $100 \mu \mathrm{l}$ clear supernatant was transferred in 96-well plates and analyzed using LC-MS/MS. Chromatographic separation was achieved using a Kinetex EVO C18 column $(3 \mu \mathrm{m}$, $100 \times 4.6 \mathrm{~mm}$ i.d.; (Phenomenex, Torrance, CA). The system delivered a constant flow of $1 \mathrm{ml} / \mathrm{min}$, with the mobile phase consisting of $0.1 \%$ formic acid in acetonitrile and $10 \mathrm{mM}$ ammonium formate injected at a volume of $5 \mu \mathrm{l}$ at a temperature of $45^{\circ} \mathrm{C}$. Detection of SMM-295 and standards was performed with the QTRAP 4000 LC/triple-quadruple mass spectrometer (SCIEX, Concord, ON, Canada). A calibration curve was constructed and validated with spiked samples in either plasma or kidney homogenates.

\section{Renal IRI}

Male C57BL/6J mice (aged 6 to 7 weeks; 19.4-25.5 g) were obtained from the Jackson Laboratory (Bar Harbor, ME) and allowed to acclimate for at least 3 days before bilateral renal IRI surgeries were performed. This study utilizes unilateral and bilateral IRI surgical models using a protocol that is well established and was published by our laboratory (Regner et al., 2011; White et al., 2014; Pressly et al., 2017). Animal studies were conducted in accordance with Committee on Care and Use of Laboratory Animal Resources guidelines (National Research Council, 2011). All protocols were approved by the Institutional Animal Care and Use Committee at the University of Tennessee Health Science Center in Memphis. All mice were provided ad libitum access to mouse chow and water prior to and after the surgical procedures and were group housed in cages with up to five mice per cage. The mice were anesthetized with pentobarbital (50-80 mg/kg i.p.) before IRI was performed. 
For the gene expression studies to detect changes in CB2 receptors, unilateral IRI was performed, in which a renal flank incision was made on the left side of the mouse. The left kidney was isolated and clamped at the renal hilus using microisolator clamps. After the kidneys were clamped, they were placed back into the abdominal area and body temperature was maintained between 35 and $37^{\circ} \mathrm{C}$ as monitored by a rectal temperature probe. After 27 minutes, the clamps were removed and the mice were allowed to recover for 24, 72, or 168 hours. At each time point, mice were euthanized to collect the IRI and contralateral (uninjured) kidneys, which were kept on dry ice and frozen at $-80^{\circ} \mathrm{C}$ until isolation of total RNA.

For the pharmacology studies, we performed bilateral IRI on the kidneys, in which flank incisions on both sides of the mice were performed to clamp the renal hilus. The renal ischemia was shortened to 24.5 minutes to increase the likelihood of survival over the 48-hour experimental period. Immediately upon removal of the microisolator clamps to initiate reperfusion, either CB2 receptor agonist SMM-295 (6 mg/kg i.p.) or CB2 receptor inverse agonist SMM-189 ([4-(3,5-dichlorophenyl)-35-dihydroxy-phenyl]phenyl-methanone) (6 mg/kg i.p.) was administered. Vehicle solution was used as a control in a separate group of mice. The kidneys were subsequently monitored for restoration of blood perfusion prior to closure of the wounds. All surgeries were conducted under aseptic conditions and all mice were administered buprenorphine for pain management and antibiotics, if needed, after the surgery and during the remainder of the experimental period. After 24 hours, another dose of vehicle, SMM-189 (6 mg/kg i.p.), or SMM-295 (6 mg/kg i.p.) was administered to each of the mice. The mice were euthanized using pentobarbital after either 24 or 48 hours, and the kidneys were either harvested for fixation in neutral buffer formalin to perform histology or were immediately frozen on dry ice to examine protein expression changes.

\section{Reverse Transcription Polymerase Chain Reaction Analysis for CB2 Receptor mRNA}

Total RNA was extracted from IRI-treated and contralateral kidneys using TRIzol reagent as previously described in our laboratory (Lenarczyk et al., 2015). DNAse treatment was performed on the total RNA, and the RNA was re-extracted with TRIzol reagent. Reverse transcription was performed using SuperScript III reverse transcription kit (Life Technologies). Upon completion of the reverse transcription step, polymerase chain reaction was performed using specific TaqMan primers targeted to the Cnr2 and $18 \mathrm{~s}$ cDNA. Polymerase chain reaction product formation was calculated by the delta delta $\mathrm{Ct}\left(\Delta \Delta \mathrm{C}_{\mathrm{T}}\right)$ method, as previously performed by our laboratory (Lenarczyk et al., 2015). The resulting fold change of $C n r 2$ mRNA is the difference between the injured and uninjured kidneys normalized to $18 \mathrm{~s}$ mRNA to control for variation between samples.

\section{Serum Markers of Renal Injury}

Blood samples were collected in citrate-coated tubes after 24 and 48 hours after renal IRI, and plasma was isolated by differential centrifugation. Creatinine levels were measured by LC-MS/MS (University of Alabama Department of Biochemistry, Birmingham, AL). Neutrophil gelatinase-associated lipocalin (NGAL) was measured by enzyme-linked immunosorbent assay (catalog number 89189; Abcam, Cambridge, MA).

\section{Histologic Analysis of the Kidney}

Formalin-fixed, paraffin-embedded kidneys were sectioned $(4-\mu \mathrm{m}$ thick), deparaffinized using xylene, dehydrated using increasing concentrations of ethanol, and stained with hematoxylin and eosin. Tubular damage was determined as a percentage of the total tubules by using images at $40 \times$ magnification using previously published criteria (Regner et al., 2011; White et al., 2014). To assess the proliferative status of the kidney, epitope retrieval was performed on the deparaffinized sections and immunostained for PCNA (antimouse PCNA; 1:250 dilution) using a previously described staining protocol (Kwon et al., 2012). Apoptosis was detected by terminal deoxynucleotidyl transferase-mediated digoxigenin-deoxyuridine nick-end labeling (TUNEL) staining (Promega, Madison, WI). TUNEL- and PCNA-positive cells were detected by the presence of DAB (3,3'-diaminobenzidine) precipitates, and hematoxylin was used as a counterstain. The sections were mounted and coverslipped for imaging at $40 \times$ magnification using an EVOS light microscope. Slides were deidentified and positive cell counting was performed in a blind manner in which at least five different sections were studied from multiple sections in each mouse kidney. The mouse sections were appropriately grouped after the counting of the tissue sections and were calculated as a percentage of the total number of nuclei counted. Protein lysates were also isolated from vehicle- and SMM295-treated mouse kidneys after bilateral IRI for immunoblot analysis.

\section{Hypoxia/Reoxygenation Injury in NRK-52E Cells}

Protein lysates were isolated from normal rat kidney NRK-52E cells treated with SMM-295 (1, 2, and $10 \mathrm{mM})$ for 15 minutes using established protocols in our laboratory (Park et al., 2008; Regner et al., 2011; Kwon et al., 2012; White et al., 2014). In addition, NRK$52 \mathrm{E}$ cells were incubated for 12 hours in an incubator containing $4 \%$ oxygen and $5 \%$ carbon dioxide. After the hypoxic period, the cells were incubated in normal oxygen conditions in media containing either $2 \mu \mathrm{M}$ SMM-295 or an equal volume of vehicle (DMSO) for 3 hours and lysates were collected for Western blot analysis.

\section{Immunoblot Analysis}

Protein samples were loaded onto a 4\%-20\% gradient SDS-PAGE gel for size fractionation, transferred onto a PVDF membrane, and incubated with primary antibodies (phospho- and total Akt; catalog numbers 9721 and 9272), extracellular signal-regulated kinase 1/2 (catalog numbers 8101 and 9102), p38 mitogen-activated protein kinase (MAPK) (catalog numbers 9211 and ab31828; Abcam), Bcl-xL (catalog number 2764), cleaved caspase 3 (CC3; catalog number 9665), and Bcl-2 (catalog number 2870) from Cell Signaling Technologies, unless otherwise mentioned, at a 1:1000 dilution overnight in $4^{\circ} \mathrm{C}$ conditions. Secondary goat anti-rabbit or anti-mouse horseradish peroxidase-linked IgG (1:1500 dilution; Cell Signaling Technologies; catalog numbers 7074 and 7076) secondary antibody was used for detection by chemiluminescence. Membranes were scanned using the Bio-Rad chemiluminescent detection system (Bio-Rad, Hercules, CA), and band intensities were calculated by ImageJ software (National Institutes of Health, Bethesda, MD). $\beta$-actin (1:8000, catalog number MA515739HRP; Thermo Fisher Scientific) was used as the loading control, and the relative expression of protein levels was calculated by normalizing band intensity values of the proteins of interest to either one of the loading controls.

\section{Statistical Analysis}

The data and statistical analysis comply with the recommendations on experimental design and analysis in pharmacology (Curtis et al., 2015). All values are shown as means \pm S.E.M. using GraphPad Prism software (version 6.0; GraphPad Inc., La Jolla, CA). Either an unpaired $t$ test or one-way analysis of variance was performed using Student-Newman-Keuls post hoc analysis to confirm significant differences $(P<0.05)$ between animal groups. Post hoc testing was only performed if $F$ achieved $P<0.05$ and there was no significant variance in homogeneity. For the ACTOne data, nonlinear analysis was performed. 


\section{Results}

\section{Synthesis of SMM-295}

The chemical structure of SMM-295 is shown in Fig. 1A, and its synthesis was conducted as previously described in Moore et al. (2011) with minor modifications (see Supplemental Scheme 1).

\section{Molecular Modeling of SMM-295}

No experimental CB2 structures are currently available from methods such as X-ray or nuclear magnetic resonance spectroscopy. However, there is a long history of use of protein models for study of the CB2 receptor and its interactions with ligands (Cichero et al., 2011; Brents et al., 2012; Kusakabe et al., 2013; Feng et al., 2014; Dore et al., 2016; Hu et al., 2016). As is typical for GPCRs, full agonists and partial agonists bind to and/or stabilize the active state of the CB2 receptor. The extra-precision GlideScore docking scores and $\Delta \mathrm{G}$ for SMM-295 were calculated to be -11.18 and $82.41 \mathrm{kcal} / \mathrm{mol}$, respectively. Figure 2 shows the predicted binding mode of SMM-295 to the CB2 receptor active-state model. The docking analysis reveals that the C-ring (thiophene) resides in a deep pocket and interacts with one of the two toggle-switch residues, Trp258, through aromatic $\pi$ - $\pi$ interaction. This binding pose stabilizes the tryptophan side chain dihedral angle $\chi 1$ in the trans conformation, which is necessary for CB2 activation (Hurst et al., 2010; Lucchesi et al., 2014), and helps to maintain a disconnect between the toggle-switch residues, Phe117 and Trp258. In addition, the dimethyl linker between the B- and C-rings showed favorable hydrophobic interactions with key residues Phe197, Ile198, Trp258, and Leu262. SMM-295 is further stabilized by H-bond interactions with Thr114 and Val261 residues and a strong array of hydrophobic interactions of the A-ring and the B-ring with neighboring hydrophobic residues of CB2. The A-ring and B-ring also exhibited $\pi-\pi$ interactions with Trp172 and Trp194, respectively.

\section{Receptor Binding and Activity of SMM-295 In Vitro}

Genetically modified HEK 293 cells over-expressing CB1 or CB2 receptors were evaluated to assess the binding properties and functional activities by SMM-295 using the ACTOne technology and receptor binding assays. The $K_{\mathrm{d}}$ and $B_{\max }$ values for SMM-295 in CB1-expressing cells were $1.98 \pm 0.6$ $\mathrm{nM}$ and $8.47 \pm 2.35 \mathrm{pmol} / \mathrm{mg}(n=6)$, respectively. In CB2expressing cells, these values were $1.65 \pm 0.5 \mathrm{nM}$ and $3.18 \pm$ $0.1 \mathrm{pmol} / \mathrm{mg}$ for $K_{\mathrm{d}}$ and $B_{\max }(n=6)$, respectively. The affinity of SMM-295 for CB2 was measured to be $12 \pm 2.26 \mathrm{nM}$ with 31-fold selectivity over CB1 (379 $\pm 53 \mathrm{nM}$; Table 1). The potency of SMM-295 at CB2 was comparable to the affinity, with an $\mathrm{EC}_{50}$ value of $18.1 \pm 1.45 \mathrm{nM}$ and efficacy of $54 \%$ to prevent cAMP production (Fig. 3). Compared with our internal standard, SMM-295 was 2-fold less potent than CP 55,940 $\left(\mathrm{EC}_{50}=8.74 \mathrm{nM}\right)$, which had a $77 \%$ efficacy to inhibit cAMP production. At much higher doses, SMM-295 could act as a weak agonist of CB1 with an interpolated potency of $1190 \pm$ $22 \mathrm{nM}$ and only $21 \%$ suppression of cAMP at $1 \mu \mathrm{M}$ (Fig. 3A). In the parental cell line containing only the CNG ion channel, increasing concentrations of SMM-295 did not decrease the cAMP response, which confirmed that the observed cAMP response was not due to off-target effects. Moreover, in the hERG assay, higher doses of SMM-295 (10 $\mu \mathrm{M})$ exhibited only minimal inhibition of the channel $(4 \% \pm 3 \%$; Table 1$)$. Using ADMET Predictor, the calculated $\log \mathrm{P}(\mathrm{S}+\log \mathrm{P})$, which has been a reliable predictor for the ratio of lipid solubility to water solubility and for membrane-crossing capability (Tetko IV et al. 2009), for SMM-295 was 5.6 and the calculated water solubility $\mathrm{S}+\mathrm{Sw}$ was $0.0036 \mathrm{mg} / \mathrm{ml}$. By comparison, another common CB2 agonist, JWH-133, had considerably higher $\mathrm{S}+\log \mathrm{P}(7.78)$ and lower $\mathrm{S}+\mathrm{Sw}(0.000019 \mathrm{mg} / \mathrm{ml})$, demonstrating that SMM-295 had improved biophysical properties that could potentially increase its ability to exert a biologic response in vivo.

The rat NRK-52E proximal tubule cell line was incubated with increasing doses of SMM-295 (0-10 $\mu \mathrm{M})$ for 15 minutes and protein lysates were analyzed for changes in extracellular signal-regulated kinase 1/2 (ERK1/2), p38 MAPK, and Akt activation by immunoblot analysis. Figure $3 \mathrm{~B}$ shows that there was a dose-dependent increase in the activation (phosphorylation) from 0 to $10 \mu \mathrm{M}$ after exposure to SMM-295.
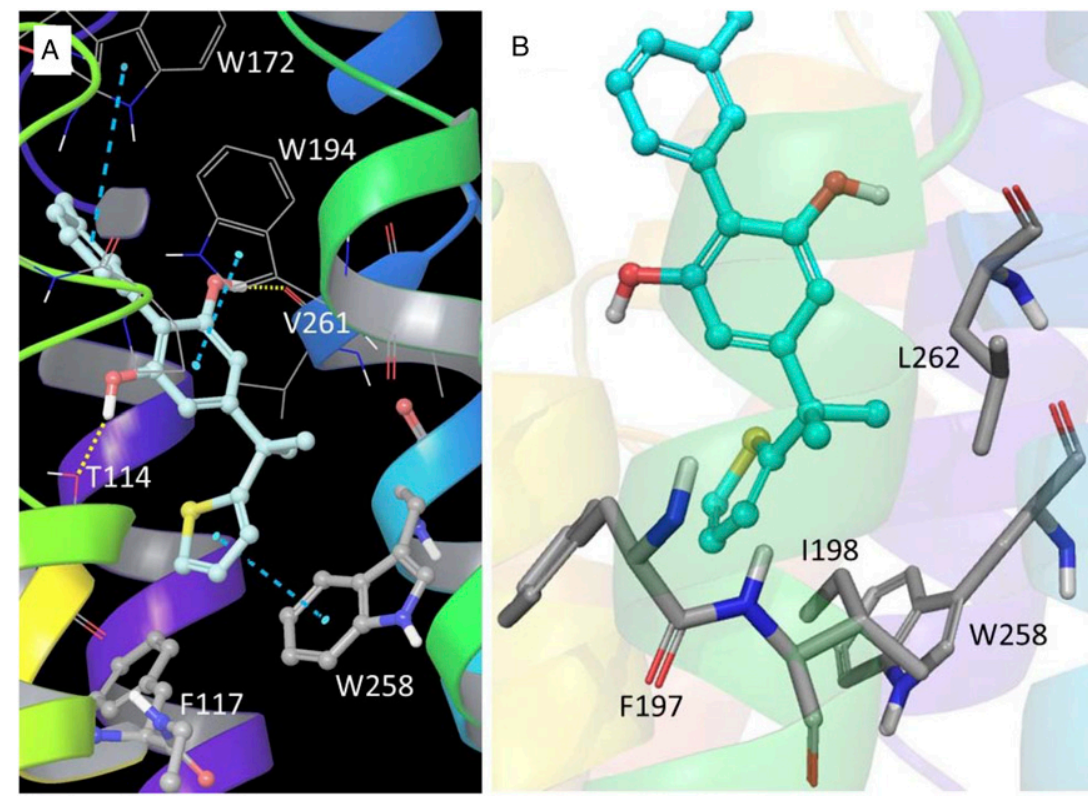

Fig. 2. Computational modeling of the CB2 receptor with SMM-295. Key interactions of SMM-295 with the CB2 receptor active-state model after docking. (A) The C-ring of SMM-295 (carbon, light cyan) is stacked over Trp258 but further away from Phe117 $(\pi-\pi$ stacking is shown with turquoise dashed lines). The A-ring of SMM295 is stacked with Trp172, while the B-ring is stacked with Trp194. Hydrogen bonding interactions of the B-ring hydroxyls were found with Thr114 and with the backbone carbonyl of Val261 (shown as dotted yellow lines). (B) Hydrophobic residues Phe197, Ile198, Trp258, and Leu262 (carbon, gray) are positioned close to the dimethyl linker site of SMM-295 (carbon, cyan). 
TABLE 1

Physiochemical and biochemical assays for SMM-295

\begin{tabular}{|c|c|c|c|c|c|c|}
\hline Assay & Species & Receptor & Parameter & Value & $\mathrm{CB} 1 / \mathrm{CB} 2$ & Efflux Ratio (B-A/A-B) \\
\hline \multirow[t]{2}{*}{ Binding } & Human & $\mathrm{CB} 1$ & $K_{\mathrm{i}}$ & $379 \pm 53 \mathrm{nM}$ & 31 & \\
\hline & Human & CB2 & $K_{\mathrm{i}}$ & $12 \pm 2.26 \mathrm{nM}$ & & \\
\hline cAMP inhibition & Human & CB1 & $\mathrm{EC}_{50}$ & $1190 \pm 22.1 \mathrm{nM}$ & 66 & \\
\hline \multirow[t]{2}{*}{ Protein binding ( $\%$ bound) } & Human & & & $>99.9$ & & \\
\hline & Mouse & & & $>99.9$ & & \\
\hline \multirow{2}{*}{ hERG (\% inhibition) } & Human & & $10 \mu \mathrm{M}$ & $4 \pm 3$ & & \\
\hline & Human & & $1 \mu \mathrm{M}$ & $<0.1 \%$ & & \\
\hline \multirow{2}{*}{ Permeability } & Human & & $\mathrm{P}_{\mathrm{app}} \mathrm{A} \rightarrow \mathrm{B}(+$ verapamil $)$ & $7.9 \pm 0.1 \times 10^{-6} \mathrm{~cm} / \mathrm{s}$ & & 0.9 \\
\hline & Human & & $\mathrm{P}_{\mathrm{app}} \mathrm{B} \rightarrow \mathrm{A}(+$ verapamil $)$ & $6.7 \pm 0.2 \times 10^{-6} \mathrm{~cm} / \mathrm{s}$ & & \\
\hline
\end{tabular}

\section{Solubility, Permeability, and Metabolism of SMM-295}

SMM-295 was highly bound to plasma proteins in both mouse and humans at $>99 \%$. The high plasma binding was
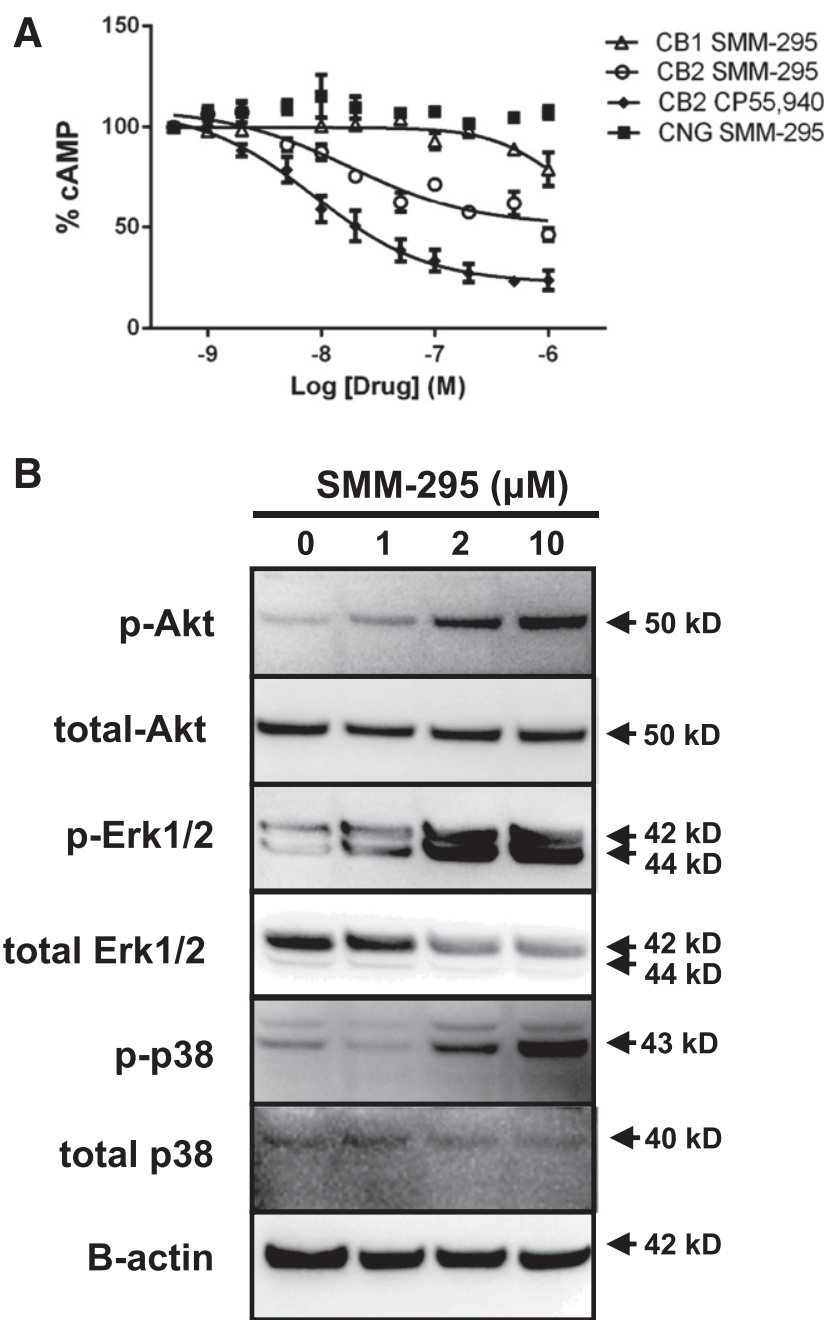

Fig. 3. (A) Functional activities of SMM-295 in the CB2 ACTOne assay (open circles), CB1 ACTOne assay (open triangles), and parental ACTOne cells containing only the CNG ion channel (filled squares). The functional activation of CB2 by the internal control (CP 55,940; filled diamonds) is shown. (B) Western blot analysis of signaling proteins after brief exposure (15 minutes) to SMM-295 in rat NRK-52E proximal tubule epithelial cells. Activation of prosurvival Akt/PKB and MAPK (ERK1/2 and p38) was detected using specific antibodies. $\beta$-actin was used as a loading control. ERK1/2, extracellular signal-regulated kinase 1/2. similar to warfarin, which was used as a positive control since it binds to human $(98.8 \% \pm 0.2 \%)$ and mouse $(96.9 \% \pm 0.2 \%)$ proteins (Table 1).

Bidirectional permeability of SMM-295 using the standard Caco-2 cell system demonstrated that SMM-295 was moderately transported through the cell (efflux ratio $=1.4$; Table 1 ) unlike loperamide (efflux ratio $=2.6$ ), which was a positive efflux drug for the activity of P-gp (data not shown). In addition, the permeability through the cell membranes was independent of P-gp activity, as determined by the lack of any change in SMM-295 transport in the presence of verapamil (Table 1).

In vitro metabolism of SMM-295 was analyzed using a panel of common P450 enzymes, including CYP1A2, CYP2C9, CYP2C19, CYP3A4, and CYP2D6. To validate the metabolism of SMM-295 by each P450 enzyme used in the assay, positive control compounds were assayed in conjunction with SMM-295. Specifically, phenacetin (CYP1A2), propranolol (CYP2D6), diclofenac (CYP2C9), lansoprazole (CYP2C19), and terfenadine (CYP3A4) were tested due to well established metabolism through each respective P450 enzyme. In summary, SMM295 was metabolized by the P450 enzymes over the 60 -minute period in the following order (from highest to lowest): CYP2C19 > CYP3A4 > CYP2D6 > CYP2C9 > CYP1A2 (Table 2). The respective calculated half-lives for SMM-295 in the presence of each P450 enzyme are provided in Table 2.

\section{In Vivo Pharmacokinetics}

After intraperitoneal injection of SMM-295 $(6 \mathrm{mg} / \mathrm{kg})$, the maximal plasma concentration $\left(C_{\max }\right.$, plasma $)$ was $304.4 \pm$ $40.3 \mathrm{ng} / \mathrm{ml}$ after 0.25 hours $\left(t_{\text {max, plasma }}\right)$ (Fig. 1B). In the kidney, there was a high concentration of SMM-295 after 0.08 hours $\left(t_{\text {max }}\right.$, kidney $)$ with an average peak value of $9826 \pm$ $5461 \mathrm{ng} / \mathrm{g}$ kidney tissue $\left(C_{\text {max, kidney }}\right)$ (Fig. 1C). Using these values, the half-life of SMM-295 was calculated at 0.25 hours, and SMM-295 could be detected in the plasma for between 4 and 8 hours.

\section{SMM-295 Protective Effects in a Mouse Model of Renal IRI}

CB2 Receptor Upregulation in the Kidney after IRI. Steady-state changes in the Cnr2 mRNA level were measured in a mouse model of unilateral IRI. In the IRItreated kidneys, Cnr2 mRNA increased after 24 hours (1.3 \pm 0.2 -fold; $n=5)$ and reached significance by 72 hours $(3.0 \pm$ 0.2 -fold; $P<0.05 ; n=5$ ) compared with uninjured kidneys (Fig. 4). The steady-state levels of CB2 mRNA trended back 
TABLE 2

In vitro $\mathrm{P} 450$ enzyme metabolism

\begin{tabular}{|c|c|c|c|c|c|c|c|c|c|c|}
\hline \multirow{2}{*}{$\begin{array}{c}\text { Parameters } \\
\text { Drug properties }\end{array}$} & \multicolumn{2}{|c|}{ CYP1A2 } & \multicolumn{2}{|c|}{ CYP2D6 } & \multicolumn{2}{|c|}{ CYP2C9 } & \multicolumn{2}{|c|}{ CYP2C19 } & \multicolumn{2}{|c|}{ CYP3A4 } \\
\hline & Phenacetin & SMM-295 & Propranolol & SMM-295 & Diclofenac & SMM-295 & Lansoprazole & SMM-295 & Terfenadine & SMM-295 \\
\hline Half-life (minutes) & 49.3 & $>60$ & $<5.0$ & 28.4 & 9.0 & 55.3 & 7.4 & 6.8 & 19.0 & 12.2 \\
\hline $\begin{array}{l}\text { Percent remaining at } 60 \\
\text { min }(+\mathrm{NADPH})\end{array}$ & 37 & 62 & 0 & 20 & 1 & 44 & 0 & 0 & 9 & 3 \\
\hline
\end{tabular}

toward normal levels at 168 hours after IRI $(0.7 \pm 0.3$-fold; $n=5$ ).

CB2 Receptor Activation Reduced Renal Injury after Renal Bilateral IRI. Blood analysis of levels of plasma creatinine (Fig. 5A) and NGAL (Fig. 5B), which are functional markers of renal injury, were examined after IRI. After renal bilateral IRI, either SMM-295 (6 mg/kg i.p.; $n=5)$ or vehicle solution $(n=7)$ was administered and creatinine levels were measured after 24 hours. Creatinine levels were significantly lower $(P<0.05)$ in mice treated with SMM-295 $(0.31 \pm$ $0.05 \mathrm{mg} / \mathrm{dl})$ compared with control mice $(n=7)$ treated with the vehicle solution $(0.75 \pm 0.16 \mathrm{mg} / \mathrm{dl})$. Similarly, significantly lower NGAL levels $(P<0.05)$ were measured in the blood from mice treated with SMM-295 $(n=5)$ compared with vehicle $(n=7)$. No change in body temperature was detected in vehicle- or SMM-295-treated mice ( $n=6$ mice/group; Fig. $5 \mathrm{C})$.

After 48 hours of reperfusion after the ischemic period, treatment with SMM-295 significantly reduced outer medullary tubular epithelial cell damage by approximately $33 \%$ $(P<0.05 ; n=5)$ compared with vehicle treatment $(61.9 \% \pm$ $2.2 \% ; n=5$ ) (Fig. 5 , D-H). Conversely, administration of a CB2 inverse agonist, SMM-189 (6 mg/kg i.p.), exaggerated the increase in plasma creatinine $(1.63 \pm 0.38 \mathrm{mg} / \mathrm{dl} ; n=5)$ compared with vehicle after 24 hours after IRI (Supplemental Fig. 1A). In addition, SMM-189 was associated with a significantly increased percentage of damaged tubules after 48 hours after IRI compared with vehicle-treated mice $(n=$ 5 mice/group; Supplemental Fig. 1B). These results demonstrate that CB2 activation by SMM-295 can prevent renal injury after AKI and that blocking activity at CB2 is detrimental in AKI.

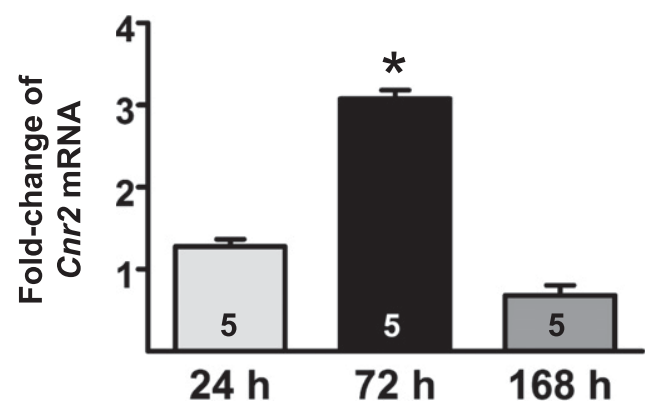

Fig. 4. Increased steady-state levels of CB2 receptor mRNA in kidneys after ischemia-reperfusion injury. Fold change of mRNA levels for CB2 receptor between contralateral and injured kidneys from wild-type male C57BL/6J mice at various time points $(24,72$, and 168 hours) after unilateral IRI. $n=5$ mice/group per time point. A $t$ test was used to confirm significant differences $(* P<0.05)$ between contralateral versus IRI kidneys at each time point.
In the SMM-295-treated kidneys, increased activation of Akt (Ser473) and total Akt was detected, which is associated with enhanced cell survival, compared with vehicle treatment (Fig. 6, A-C). In addition, Bcl-2 (Fig. 6, A and D) and Bcl-xL (Fig. 6, A and E) were also markedly elevated in the SMM295-treated mouse kidneys, which provides evidence that SMM-295 could prevent apoptosis activation. This was supported by a significantly lower number of TUNEL-positive nuclei in the outer medulla of SMM-295-treated kidneys $(1.3 \% \pm 0.3 \% ; n=5)$ compared with vehicle-treated kidneys $(4.6 \% \pm 0.6 \% ; n=5)$ (Fig. $6, \mathrm{~F}-\mathrm{H})$. The molecular evidence using the mouse kidneys from the in vivo studies suggests that SMM-295 prevented tubular epithelial cell damage by enhancing cell survival, in part by decreasing the activation of apoptotic cell death. SMM-295 decreased the levels of CC3, an indicator of apoptosis, in NRK-52E cells after hypoxic conditions (Supplemental Fig. 2). These data provide direct evidence of a decrease in apoptotic signaling molecules specifically on tubular epithelial cells using a common in vitro model of IRI. This activation of antiapoptotic signaling cascades may explain why the SMM-295-treated kidneys had a lower number of PCNA-positive epithelial cells in the outer medulla (Supplemental Fig. 3), since there would be less requirement to promote hyperplasia due to the reduced cellular damage in the presence of SMM-295.

\section{Discussion}

Endocannabinoids can play a crucial role in maintaining the normal homeostasis of the kidney via interaction with the CB1 and CB2 receptors (Howlett, 2005; Hryciw and McAinch, 2016). Recently, there are clinical cases demonstrating that exogenous cannabinoids can also lead to a disruption in normal renal function resulting in AKI (Kazory and Aiyer, 2013; Srisung et al., 2015). The mechanism by which renal function is impaired by cannabinoid signaling remains to be determined but may in part involve the differential activation of the $\mathrm{CB} 1$ and $\mathrm{CB} 2$ receptors. $\mathrm{CB} 1$ receptor activation aggravates glomerular and tubular epithelial cell damage to exacerbate decrements in renal function (Jourdan et al., 2014). In many instances, however, activation of the CB2 receptor can counteract the deleterious effects mediated by the CB1 receptor, as demonstrated in various rodent models exhibiting pathologies associated with chronic kidney disease.

In obesity-related nephropathy, activation of the CB2 receptor with AM-1241 [1-(methylpiperidin-2-ylmethyl)-3-(2iodo-5-nitrobenzoyl)indole] reduced urinary protein excretion and attenuated the appearance of fibrotic markers (Jenkin et al., 2016). Similarly, chronic renal function was improved in the presence of selective CB2 activation using either an experimental or genetic mouse model of diabetes (Barutta et al., 2011; Zoja et al., 2016). Urinary albuminuria and 

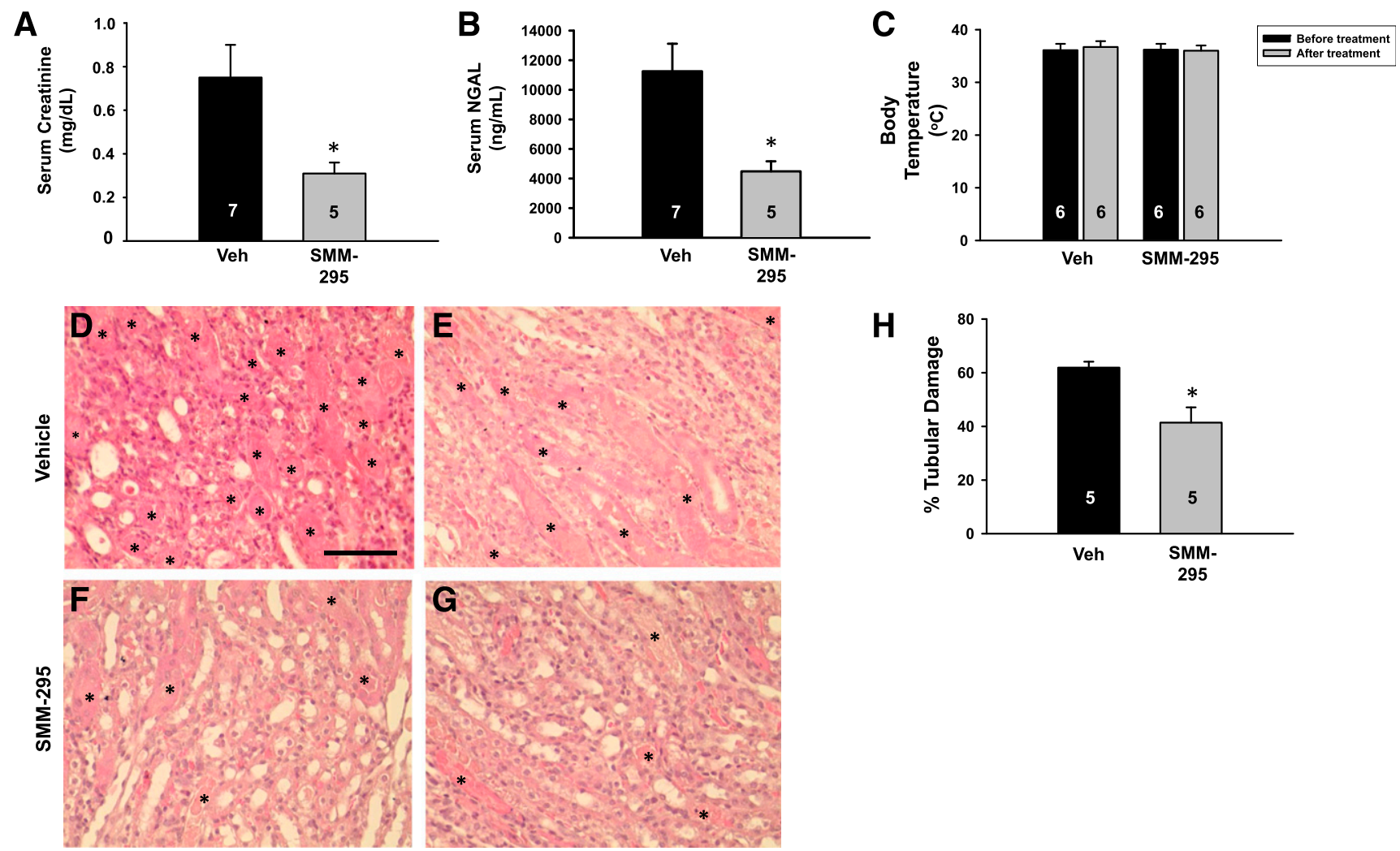

Fig. 5. Serum and tissue analyses from mice after bilateral IRI in the presence and absence of CB2 receptor activation. (A and B) Plasma measurements were obtained for creatinine (A) and NGAL (B) from IRI-treated mice administered either vehicle (Veh) or SMM-295 after 24 hours. (C) Rectal body temperature was measured in IRI-treated mice after 24 hours prior and after administration with either vehicle $(n=6)$ or SMM-295 $(6 \mathrm{mg} / \mathrm{kg}$ i.p.; $n=6)$. (D-H) Representative outer medullary kidney images from four different IRI-treated mouse kidneys administered either vehicle (D and E) or SMM-295 $(6 \mathrm{mg} / \mathrm{kg}$ i.p.; $\mathrm{F}$ and G) after 48 hours. Asterisks indicate cast-containing tubules. (H) Tubular damage was graphed as a percentage of the total number of tubules from vehicle- or SMM-295-treated kidney sections. Animal numbers are shown in the bars. A $t$ test (A, B, and $\mathrm{H})$ or analysis of variance (C) was used to confirm significant differences $(* P<0.05)$ between groups. Scale bar, $100 \mu \mathrm{m}$.

podocyte protein loss was dramatically reduced in the AM-1241-treated mice compared with the vehicle group (Barutta et al., 2011). Consistent with these results, reduced glomerular damage was observed in the black and tan, brachyuric (BTBR) ob/ob leptin-deficient mouse model of progressive diabetic nephropathy after administration of another CB2 agonist, HU-910 [(1S,4R)-2-(2,6-dimethoxy-4-(2methyloctan-2-yl)phenyl)-7,7-dimethylbicyclo[2.2.1]hept-2en-1-yl)methanol] (Zoja et al., 2016). Although the exact mechanism by which the renal architecture and function was preserved is not fully described, it may involve CB2 receptor-dependent inhibition of the immune system (Jenkin et al., 2016). Diabetic nephropathy is associated with increased chemokine production, inflammatory cell infiltration, and the consequent release of reactive oxygen species and inflammatory mediators that activate tubular cell apoptosis (Mukhopadhyay et al., 2010b). The CB2 receptor has been demonstrated to be highly produced in immune cells (Klein et al., 2003; Cabral and Griffin-Thomas, 2009), which is an important cell type that is recruited to the kidney upon the presentation of a damage response by injured tubular epithelial cells, especially during diabetic nephropathy (Mukhopadhyay et al., 2010b). Glomerular damage was lessened by decreased accumulation of monocytes and macrophages in the presence of HU-910, a CB2 agonist (Zoja et al., 2016). It would appear that chronic treatment with CB2 receptor agonists limits inflammatory signaling by reducing oxidative stress, which can help to attenuate the nephropathic injury by possibly preventing tubular cell apoptosis (Mukhopadhyay et al., 2010b; Barutta et al., 2011).

The precise nature of the role of the cannabinoid receptors in the kidney during AKI remains to be fully understood. Cannabidiol, a modest CB2 inverse agonist and weak CB1 antagonist (Thomas et al., 2007), was shown to have a beneficial effect on renal function after IRI (Fouad et al., 2012). In this study, the specific receptor activation was not evaluated, but the protection of the kidney was associated with reduced expression of proinflammatory factors (Fouad et al., 2012). In another study using a rodent model of renal IRI, tubular epithelial cell damage was prevented after dosedependent administration of either CB1 or CB2 receptor agonists (Feizi et al., 2008).

In our study, we synthesized SMM-295, which demonstrated highly selective activation of the CB2 receptor that could provide beneficial protection of the renal tubular epithelial cell structure and function. SMM-295 inhibited cAMP production and also activated downstream MAPK signaling complexes consistent with the known actions of CB2 activation. Pharmacokinetic analyses showed that SMM295 had a relatively short half-life, which was likely attributed to the metabolism by P450 enzymes, most notably CYP2C19 and CYP3A4. The short half-life for CB2 agonists remains a problem for most of the well characterized analogs in the literature (Soethoudt et al., 2017). There was, however, 

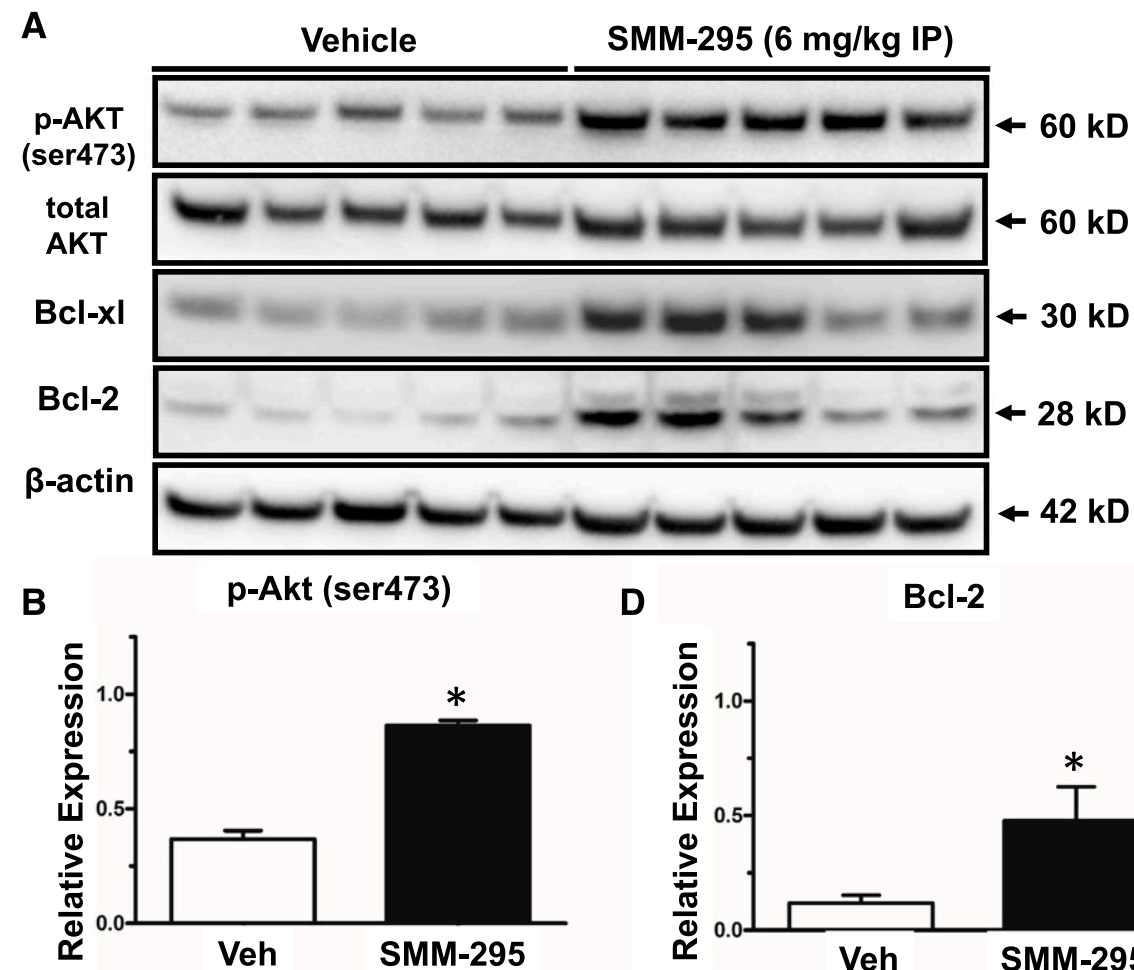

C
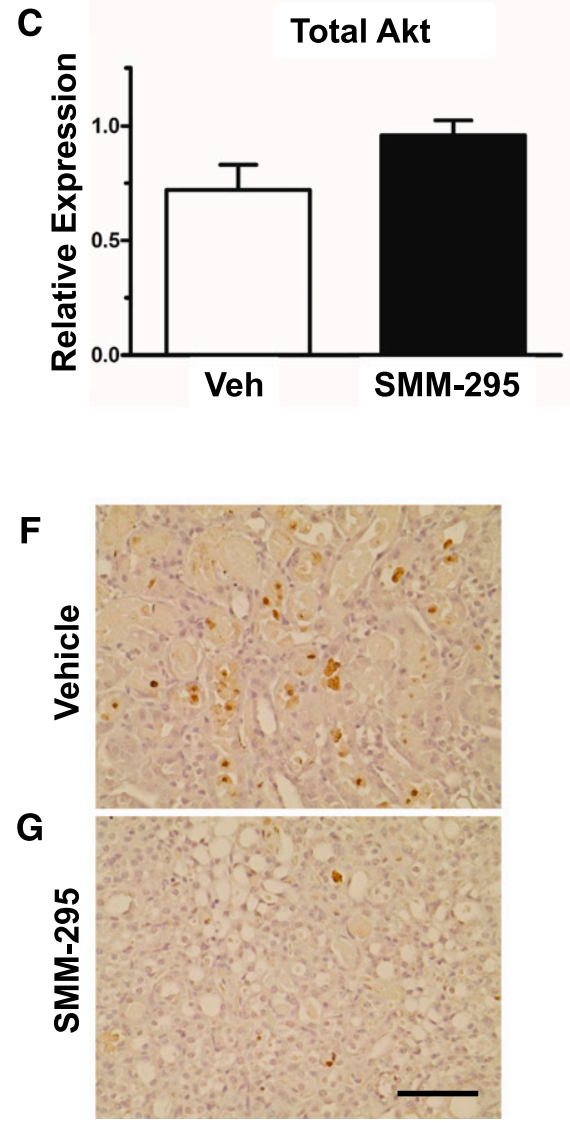

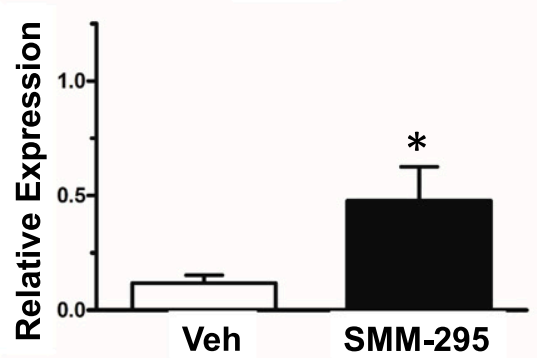

E

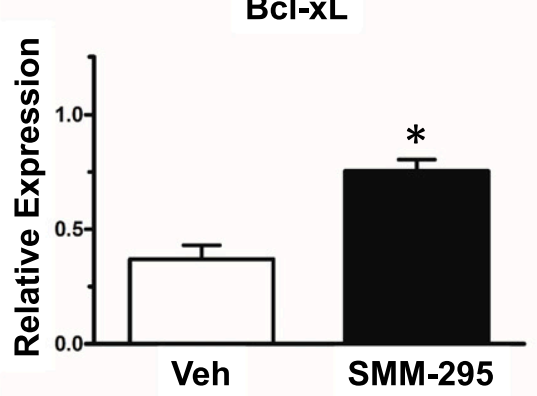

H

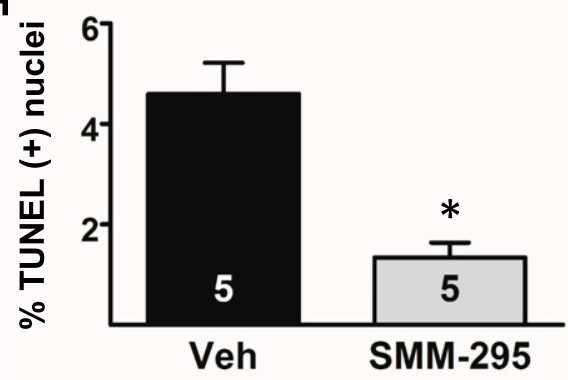

Fig. 6. SMM-295 improved renal cell survival by reducing apoptotic signaling. (A) Representative Western blot analyses of prosurvival Akt (phospho- and total) and antiapoptotic Bcl-2 and Bcl-xL using protein lysates from mouse kidneys treated with vehicle $(n=5)$ or SMM-295 $(n=5)$. $\beta$-actin was used as a loading control. Arrows on the right indicate expected band size for the detected proteins. (B-E) Densitometric band intensities were determined by ImageJ analysis for p-Akt (Ser473) (B), total Akt (C), Bcl-2 (D), and Bcl-xL (E). (F and G) Representative images of TUNEL staining in vehicletreated (F) or SMM-295-treated (G) mice after IRI. (H) TUNEL-positive nuclei were counted and graphed out of 1000 total nuclei counted in the sections. A $t$ test was used to confirm significant differences $(* P<0.05)$ between groups. Scale bar, $100 \mu \mathrm{m}$. 
accumulation of SMM-295 in the kidney, which could obviate the rapid decrement of circulating drug and provide more opportunity for renal cell signal activation, particularly during times of renal injury that would negatively impact clearance of exogenous drugs. Consistent with our study, Nettekoven et al. (2016) showed that their newly synthesized CB2 receptor agonist could reduce circulating creatinine after renal IRI. Moreover, a partial CB2 agonist, LEI-101 (3cyclopropyl-1-[[4-[6-[(1,1-dioxido-4-thiomorpholinyl)methyl]5-fluoro-2-pyridinyl]phenyl]methyl]-2,4-imidazolidinedione), was capable of attenuating cisplatin-induced tubular damage by reducing oxidative stress and inflammation in mice (Mukhopadhyay et al., 2016). Administration of LEI-101 in mice deficient in the full-length CB2 receptor confirmed that the CB2 receptor was responsible for the prevention of the cisplatin-dependent tubular injury (Mukhopadhyay et al., 2016). In addition, we showed that an inverse CB2 agonist, SMM-189, could exacerbate the tubular injury and promote renal damage. These studies provide strong evidence that exogenous administration of cannabinoid agonists to the $\mathrm{CB} 2$ receptor can protect the kidney during states of AKI. The mechanism by which the tubular epithelial cells were protected by CB2 receptor activation needs further investigation, but it may involve diverse signal transduction regulation of the various $\mathrm{G} \alpha \beta \gamma$ complexes in the tubular epithelial cells. The CB2 receptor is well established to activate Goi subunits to inhibit cAMP production, but other studies have also shown that the CB2 receptor can interact with $\mathrm{G} \alpha \mathrm{q}$ to promote activation of phospholipase C (Howlett, 2005). Phospholipase $\mathrm{C}$ activation is known to activate Akt, which is involved in promoting cell survival and reducing the activation of proapoptotic pathways (Datta et al., 1999). Of these pathways, activation of Akt can lead to increases in the antiapoptotic proteins Bcl-2 and Bcl-XL, which was observed in our study. Bcl-2 and Bcl-XL reside in the mitochondrial membrane and act to promote cellular survival through the inhibition of actions initiated by other proapoptotic proteins that would otherwise cause a release of mitochondrial contents like cytochrome $c$ (Chao and Korsmeyer, 1998). Cytochrome $c$ from the mitochondria intrinsically activates caspase 3 leading to increased cleavage forms, which acts to degrade various cellular components during apoptosis (Porter and Jänicke, 1999). Our study demonstrated that CB2 activation in vivo leads to increased phosphorylation of Akt with a concomitant increase in the Bcl-2 family proteins. This subsequently reduced apoptosis in sublethally injured tubular epithelial cells, and this could have accounted for the increase in function and decrease in tubular damage seen in our study. Moreover, we confirmed that proximal tubular cells in vitro could suppress CC3 levels after hypoxia in the presence of SMM-295. Further in vitro studies are still needed to confirm that the signaling protein changes can be directly attributed to the activation of the CB2 receptor and are not due to compensation by the injured renal cells caused by activation or suppression of other pathways.

Alternatively, the beneficial effects of selective CB2 receptor activation may be attributed to a systemic effect preventing immune cell recruitment to the sites of injury similar to the effects observed during chronic kidney disease. The endocannabinoid system through the stimulation of its cognate receptors, CB1 and CB2, has been shown to be involved in the regulation of inflammation and immune function (Shohami et al., 2011; Witkamp and Meijerink, 2014). In particular, brain microglia, which are proposed to be important in regulating the inflammatory response in the central nervous system, upregulate expression of the CB2 receptor in response to a biologic insult (Cassano et al., 2017). It has been demonstrated that CB2 ligands attenuate the adverse effects by reducing the release of proinflammatory cytokines and chemokines (Walter et al., 2003; Ortega-Gutiérrez et al., 2005; Zarruk et al., 2012) and also regulating the activation state of microglia (Presley et al., 2015a; Bu et al., 2016). This biologic effect is critical in the kidney, since the immune system has been shown to be an important component of the early pathogenic effects on renal cell damage, including vascular and tubular epithelial cells, which can be attributed to resident and infiltrating immune cell activity (Bonventre and Yang, 2011; Basile et al., 2012). Although our findings are promising with regard to the potential therapeutic role of SMM-295 during the early phase of AKI, further studies are needed to characterize other longterm changes in renal architecture and function, such as urine concentrating mechanisms and vascular abnormalities, to fully understand the positive impact of the CB2 receptor system during kidney injury and recovery pathways. Therefore, future studies are necessary to elucidate the possible signaling pathways associated with the CB2 receptor to produce the prosurvival effects in the kidney.

In conclusion, our group has demonstrated that SMM-295 is a selective agonist of CB2 with comparable affinity, potency, and efficacy to other CB2 ligands, such as AM-1241, HU-910, and LEI-101, which have previously been evaluated in kidney disease models. This study demonstrates for the first time a direct effect of CB2 agonism on renal epithelial cells. Although studies have shown an effect of cannabinoids on cell death in other organ systems and cancer (Guzmán et al., 2002; Calvaruso et al., 2012), the effects of cannabinoid signaling on cell death can be quite diverse for a number of factors, including distinct cell types, concentration of ligand used in the treatment, and disease models being evaluated. The complexity of the endocannabinoid system provides an opportunity to develop therapeutic strategies utilizing cannabinoid receptor ligands to treat a diverse array of diseases. We believe that this study provides novel evidence of antiapoptotic signaling mediated by CB2 activation in renal ischemic injury, in which early onset of cell death signaling cascades and proliferation could play a large role in the pathophysiology of the disease. Moreover, administration of SMM-295 immediately upon reperfusion after a brief renal ischemic period reduced tubular epithelial cell damage in the outer medulla of the kidney. These data suggest that there is considerable promise in the development of SMM-295 as a potential therapeutic and that modifications to enhance its efficacy, potency, and selectivity to the CB2 receptor could lead to CB2 receptor-selective agonist analogs that will be clinically useful in the treatment of IRI and possibly other types of acute kidney disease.

\footnotetext{
Authorship Contributions

Participated in research design: Pressly, Pandey, Doerksen, Moore, Park.

Conducted experiments: Pressly, Mustafa, Abiddi, Alghamdi, Pandey, Roy, Moore, Park.
} 
Contributed new reagents or analytic tools: Moore, Mustafa.

Performed data analysis: Pressly, Pandey, Roy, Doerksen, Moore, Park.

Wrote or contributed to the writing of the manuscript: Pressly, Pandey, Doerksen, Moore, Park.

\section{References}

Barutta F, Piscitelli F, Pinach S, Bruno G, Gambino R, Rastaldi MP, Salvidio G Di Marzo V, Cavallo Perin P, and Gruden G (2011) Protective role of cannabinoid receptor type 2 in a mouse model of diabetic nephropathy. Diabetes 60:2386-2396.

Basile DP, Anderson MD, and Sutton TA (2012) Pathophysiology of acute kidney injury. Compr Physiol 2:1303-1353.

Bonventre JV and Yang L (2011) Cellular pathophysiology of ischemic acute kidney injury. J Clin Invest 121:4210-4221.

Brents LK, Medina-Bolivar F, Seely KA, Nair V, Bratton SM, Nopo-Olazabal L, Patel RY, Liu H, Doerksen RJ, Prather PL, et al. (2012) Natural prenylated resveratrol analogs arachidin-1 and -3 demonstrate improved glucuronidation profiles and have affinity for cannabinoid receptors. Xenobiotica 42:139-156.

Bu W, Ren H, Deng Y, Del Mar N, Guley NM, Moore BM, Honig MG, and Reiner A (2016) Mild traumatic brain injury produces neuron loss that can be rescued by modulating microglial activation using a CB2 receptor inverse agonist. Front Neurosci 10:449.

Cabral GA and Griffin-Thomas L (2009) Emerging role of the cannabinoid receptor CB2 in immune regulation: therapeutic prospects for neuroinflammation. Expert Rev Mol Med 11:e3.

Calvaruso G, Pellerito O, Notaro A, and Giuliano M (2012) Cannabinoid-associated cell death mechanisms in tumor models (review). Int $J$ Oncol 41:407-413.

Cassano T, Calcagnini S, Pace L, De Marco F, Romano A, and Gaetani S (2017) Cannabinoid receptor 2 signaling in neurodegenerative disorders: from pathogenesis to a promising therapeutic target. Front Neurosci 11:30.

Chao DT and Korsmeyer SJ (1998) BCL-2 family: regulators of cell death. Annu Rev Immunol 16:395-419.

Chawla LS, Eggers PW, Star RA, and Kimmel PL (2014) Acute kidney injury and chronic kidney disease as interconnected syndromes. N Engl J Med 371:58-66.

Chertow GM, Burdick E, Honour M, Bonventre JV, and Bates DW (2005) Acute kidney injury, mortality, length of stay, and costs in hospitalized patients. $J \mathrm{Am}$ Soc Nephrol 16:3365-3370.

Choe HW, Kim YJ, Park JH, Morizumi T, Pai EF, Krauss N, Hofmann KP, Scheerer P, and Ernst OP (2011) Crystal structure of metarhodopsin II. Nature 471: $651-655$.

Cichero E, Ligresti A, Allarà M, di Marzo V, Lazzati Z, D'Ursi P, Marabotti A Milanesi L, Spallarossa A, Ranise A, et al. (2011) Homology modeling in tandem with 3D-QSAR analyses: a computational approach to depict the agonist binding site of the human CB2 receptor. Eur J Med Chem 46:4489-4505.

Curtis MJ, Bond RA, Spina D, Ahluwalia A, Alexander SPA, Giembycz MA, Gilchrist A Hoyer D, Insel PA, Izzo AA, et al. (2015) Experimental design and analysis and their reporting: new guidance for publication in BJP. $\mathrm{Br} J$ Pharmacol 172:3461-3471.

Datta SR, Brunet A, and Greenberg ME (1999) Cellular survival: a play in three Akts. Genes Dev 13:2905-2927.

Deutsch DG, Goligorsky MS, Schmid PC, Krebsbach RJ, Schmid HH, Das SK, Dey SK Arreaza G, Thorup C, Stefano G, et al. (1997) Production and physiological actions of anandamide in the vasculature of the rat kidney. $J$ Clin Invest 100:1538-1546.

Dore A, Asproni B, Scampuddu A, Gessi S, Murineddu G, Cichero E, Fossa P, Merighi S, Bencivenni S, and Pinna GA (2016) Synthesis, molecular modeling and SAR study of novel pyrazolo[5,1-f][1,6]naphthyridines as CB2 receptor antagonists/ inverse agonists. Bioorg Med Chem 24:5291-5301.

Feizi A, Jafari MR, Hamedivafa F, Tabrizian P, and Djahanguiri B (2008) The preventive effect of cannabinoids on reperfusion-induced ischemia of mouse kidney. Exp Toxicol Pathol 60:405-410.

Feng Z, Alqarni MH, Yang P, Tong Q, Chowdhury A, Wang L, and Xie XQ (2014) Modeling, molecular dynamics simulation, and mutation validation for structure of cannabinoid receptor 2 based on known crystal structures of GPCRs. J Chem Inf Model 54:2483-2499.

Fouad AA, Al-Mulhim AS, and Jresat I (2012) Cannabidiol treatment ameliorates ischemia/reperfusion renal injury in rats. Life Sci 91:284-292.

Friesner RA, Murphy RB, Repasky MP, Frye LL, Greenwood JR, Halgren TA, Sanschagrin PC, and Mainz DT (2006) Extra precision glide: docking and scoring incorporating a model of hydrophobic enclosure for protein-ligand complexes. $J$ Med Chem 49:6177-6196.

Glomme A, März J, and Dressman JB (2005) Comparison of a miniaturized shakeflask solubility method with automated potentiometric acid/base titrations and calculated solubilities. J Pharm Sci 94:1-16.

Guzmán M, Sánchez C, and Galve-Roperh I (2002) Cannabinoids and cell fate. Pharmacol Ther 95:175-184.

Harder E, Damm W, Maple J, Wu C, Reboul M, Xiang JY, Wang L, Lupyan D, Dahlgren MK, Knight JL, et al. (2016) OPLS3: a force field providing broad coverage of drug-like small molecules and proteins. J Chem Theory Comput 12 : $281-296$

Heung M and Chawla LS (2014) Acute kidney injury: gateway to chronic kidney disease. Nephron Clin Pract 127:30-34.

Himanshu R, Jakir P, Pradnya H, Suneel P, and Rahul S (2013) The impact of permeability enhancers on assessment for monolayer of colon adenocarcinoma cell line (Caco-2) used in in vitro permeability assay. J Drug Deliv Ther $\mathbf{3} \cdot 20-29$.

Horváth B, Mukhopadhyay P, Kechrid M, Patel V, Tanchian G, Wink DA, Gertsch J, and Pacher P (2012) $\beta$-Caryophyllene ameliorates cisplatin-induced nephrotoxicity in a cannabinoid 2 receptor-dependent manner. Free Radic Biol Med 52:1325-1333.

Howlett AC (2005) Cannabinoid receptor signaling. Handb Exp Pharmacol 168: $53-79$.
Hryciw DH and McAinch AJ (2016) Cannabinoid receptors in the kidney. Curr Opin Nephrol Hypertens 25:459-464.

Hu J, Feng Z, Ma S, Zhang Y, Tong Q, Alqarni MH, Gou X, and Xie XQ (2016) Difference and influence of inactive and active states of cannabinoid receptor subtype CB2: from conformation to drug discovery. J Chem Inf Model 56 $1152-1163$

Hurst DP, Grossfield A, Lynch DL, Feller S, Romo TD, Gawrisch K, Pitman MC, and Reggio PH (2010) A lipid pathway for ligand binding is necessary for a cannabinoid G protein-coupled receptor. J Biol Chem 285:17954-17964.

Jenkin KA, McAinch AJ, Briffa JF, Zhang Y, Kelly DJ, Pollock CA, Poronnik P, and Hryciw DH (2013) Cannabinoid receptor 2 expression in human proximal tubule cells is regulated by albumin independent of ERK1/2 signaling. Cell Physiol Biochem 32:1309-1319.

Jenkin KA, McAinch AJ, Grinfeld E, and Hryciw DH (2010) Role for cannabinoid receptors in human proximal tubular hypertrophy. Cell Physiol Biochem 26: 879-886.

Jenkin KA, O'Keefe L, Simcocks AC, Briffa JF, Mathai ML, McAinch AJ, and Hryciw DH (2016) Renal effects of chronic pharmacological manipulation of CB2 receptors in rats with diet-induced obesity. $\mathrm{Br} J$ Pharmacol 173:1128-1142.

Jourdan T, Szanda G, Rosenberg AZ, Tam J, Earley BJ, Godlewski G, Cinar R, Liu Z, Liu J, Ju C, et al. (2014) Overactive cannabinoid 1 receptor in podocytes drives type 2 diabetic nephropathy. Proc Natl Acad Sci USA 111:E5420-E5428.

Kazory A and Aiyer R (2013) Synthetic marijuana and acute kidney injury: an unforeseen association. Clin Kidney $J$ 6:330-333.

Klein TW, Newton C, Larsen K, Lu L, Perkins I, Nong L, and Friedman H (2003) The cannabinoid system and immune modulation. J Leukoc Biol 74:486-496.

Kusakabe K, Iso Y, Tada Y, Sakagami M, Morioka Y, Chomei N, Shinonome S, Kawamoto K, Takenaka H, Yasui K, et al. (2013) Selective CB2 agonists with antipruritic activity: discovery of potent and orally available bicyclic 2-pyridones. Bioorg Med Chem 21:3154-3163.

Kwon M, Pavlov TS, Nozu K, Rasmussen SA, Ilatovskaya DV, Lerch-Gaggl A, North LM, Kim H, Qian F, Sweeney WE, Jr, et al. (2012) G-protein signaling modulator 1 deficiency accelerates cystic disease in an orthologous mouse model of autosomal dominant polycystic kidney disease. Proc Natl Acad Sci USA 109:21462-21467.

Lenarczyk M, Pressly JD, Arnett J, Regner KR, and Park F (2015) Localization and expression profile of group I and II activators of G-protein signaling in the kidney. I Mol Histol 46:123-136.

Lucchesi V, Hurst DP, Shore DM, Bertini S, Ehrmann BM, Allarà M, Lawrence L, Ligresti A, Minutolo F, Saccomanni G, et al. (2014) CB2-selective cannabinoid receptor ligands: synthesis, pharmacological evaluation, and molecular modeling investigation of 1,8-naphthyridin-2(1H)-one-3-carboxamides. J Med Chem 57: $8777-8791$.

Macedo E and Mehta RL (2009) Prerenal failure: from old concepts to new paradigms. Curr Opin Crit Care 15:467-473.

Moore BM, Bhattacharjee H, Yates CR, and Stuart L (2011), inventors, University of Tennessee Research Foundation, assignee. Tri-aryl/heteroaromatic cannabinoids and use thereof. U.S. patent 7,888,365. $2011 \mathrm{Feb} 15$.

Mukhopadhyay P, Baggelaar M, Erdelyi K, Cao Z, Cinar R, Fezza F, IgnatowskaJanlowska B, Wilkerson J, van Gils N, Hansen T, et al. (2016) The novel, orally available and peripherally restricted selective cannabinoid CB2 receptor agonist LEI-101 prevents cisplatin-induced nephrotoxicity. Br J Pharmacol 173:446-458.

Mukhopadhyay P, Pan H, Rajesh M, Bátkai S, Patel V, Harvey-White J, Mukhopadhyay B, Haskó G, Gao B, Mackie K, et al. (2010a) CB1 cannabinoid receptors promote oxidative/nitrosative stress, inflammation and cell death in a murine nephropathy model. Br J Pharmacol 160:657-668.

Mukhopadhyay P, Rajesh M, Pan H, Patel V, Mukhopadhyay B, Bátkai S, Gao B, Haskó G, and Pacher P (2010b) Cannabinoid-2 receptor limits inflammation, oxidative/ nitrosative stress, and cell death in nephropathy. Free Radic Biol Med 48:457-467.

National Research Council (2011) Guide for the Care and Use of Laboratory Animals, 8th ed, National Academies Press, Washington, DC.

Nettekoven M, Adam JM, Bendels S, Bissantz C, Fingerle J, Grether U, Grüner S, Guba W, Kimbara A, Ottaviani G, et al. (2016) Novel triazolopyrimidine-derived cannabinoid receptor 2 agonists as potential treatment for inflammatory kidney diseases. ChemMedChem 11:179-189.

Ortega-Gutiérrez S, Molina-Holgado E, Arévalo-Martín A, Correa F, Viso A, LópezRodríguez ML, Di Marzo V, and Guaza C (2005) Activation of the endocannabinoid system as therapeutic approach in a murine model of multiple sclerosis. FASEB $J$ 19:1338-1340.

Park F, Sweeney WE, Jia G, Roman RJ, and Avner ED (2008) 20-HETE mediates proliferation of renal epithelial cells in polycystic kidney disease. J Am Soc Nephrol 19:1929-1939.

Porter AG and Jänicke RU (1999) Emerging roles of caspase-3 in apoptosis. Cell Death Differ 6:99-104.

Presley C, Abidi A, Suryawanshi S, Mustafa S, Meibohm B, and Moore BM (2015a) Preclinical evaluation of SMM-189, a cannabinoid receptor 2-specific inverse agonist. Pharmacol Res Perspect 3:e00159.

Presley CS, Mustafa SM, Abidi AH, and Moore BM, II (2015b) Synthesis and biological evaluation of $\left(3^{\prime}, 5^{\prime}\right.$-dichloro-2,6-dihydroxy-biphenyl-4-yl)-aryl/alkylmethanone selective CB2 inverse agonist. Bioorg Med Chem 23:5390-5401.

Pressly JD, Hama T, Brien SO, Regner KR, and Park F (2017) TRIP13-deficient tubular epithelial cells are susceptible to apoptosis following acute kidney injury. Sci Rep 7:43196.

Rasmussen SG, Choi HJ, Fung JJ, Pardon E, Casarosa P, Chae PS, Devree BT, Rosenbaum DM, Thian FS, Kobilka TS, et al. (2011a) Structure of a nanobodystabilized active state of the $\beta(2)$ adrenoceptor. Nature 469:175-180.

Rasmussen SG, DeVree BT, Zou Y, Kruse AC, Chung KY, Kobilka TS, Thian FS, Chae PS, Pardon E, Calinski D, et al. (2011b) Crystal structure of the $\beta 2$ adrenergic receptor-Gs protein complex. Nature 477:549-555.

Reggio PH (2010) Endocannabinoid binding to the cannabinoid receptors: what is known and what remains unknown. Curr Med Chem 17:1468-1486. 
Regner KR, Nozu K, Lanier SM, Blumer JB, Avner ED, Sweeney WE, Jr, and Park F (2011) Loss of activator of G-protein signaling 3 impairs renal tubular regeneration following acute kidney injury in rodents. FASEB $J$ 25:1844-1855.

Sali A and Blundell TL (1993) Comparative protein modelling by satisfaction of spatial restraints. J Mol Biol 234:779-815.

Sherman W, Day T, Jacobson MP, Friesner RA, and Farid R (2006) Novel procedure for modeling ligand/receptor induced fit effects. J Med Chem 49:534-553.

Shohami E, Cohen-Yeshurun A, Magid L, Algali M, and Mechoulam R (2011) Endocannabinoids and traumatic brain injury. Br J Pharmacol 163:1402-1410.

Soethoudt M, Grether U, Fingerle J, Grim TW, Fezza F, de Petrocellis L, Ullmer C, Rothenhäusler B, Perret C, van Gils N, et al. (2017) Cannabinoid CB2 receptor ligand profiling reveals biased signalling and off-target activity. Nat Commun 8 : 13958

Srisung W, Jamal F, and Prabhakar S (2015) Synthetic cannabinoids and acute kidney injury. Proc (Bayl Univ Med Cent) 28:475-477.

Tetko IV and Poda GI (2009) Property-based $\log \mathrm{P}$ prediction, in Molecular Drug Properties: Measurement and Prediction (Mannhold R ed) pp 381-406, WileyVCH, Weinheim, Germany.

Thomas A, Baillie GL, Phillips AM, Razdan RK, Ross RA, and Pertwee RG (2007) Cannabidiol displays unexpectedly high potency as an antagonist of CB1 and CB2 receptor agonists in vitro. Br J Pharmacol 150:613-623.

Walter L, Franklin A, Witting A, Wade C, Xie Y, Kunos G, Mackie K, and Stella N (2003) Nonpsychotropic cannabinoid receptors regulate microglial cell migration. $J$ Neurosci 23:1398-1405.

Wang HE, Muntner P, Chertow GM, and Warnock DG (2012) Acute kidney injury and mortality in hospitalized patients. Am $J$ Nephrol 35:349-355.

Warne T, Moukhametzianov R, Baker JG, Nehmé R, Edwards PC, Leslie AG, Schertler GF, and Tate CG (2011) The structural basis for agonist and partial agonist action on a $\beta(1)$-adrenergic receptor. Nature 469:241-244.
White SM, North LM, Haines E, Goldberg M, Sullivan LM, Pressly JD, Weber DS, Park F, and Regner KR (2014) G-protein $\beta \gamma$ subunit dimers modulate kidney repair after ischemia-reperfusion injury in rats. Mol Pharmacol 86:369-377.

Witkamp R and Meijerink J (2014) The endocannabinoid system: an emerging key player in inflammation. Curr Opin Clin Nutr Metab Care 17:130-138.

Yang L, Humphreys BD, and Bonventre JV (2011) Pathophysiology of acute kidney injury to chronic kidney disease: maladaptive repair. Contrib Nephrol 174:149-155.

Zarruk JG, Fernández-López D, García-Yébenes I, García-Gutiérrez MS, Vivancos J, Nombela F, Torres M, Burguete MC, Manzanares J, Lizasoain I, et al. (2012) Cannabinoid type 2 receptor activation downregulates stroke-induced classic and alternative brain macrophage/microglial activation concomitant to neuroprotection. Stroke 43:211-219.

Zhang Y, Xie Z, Wang L, Schreiter B, Lazo JS, Gertsch J, and Xie XQ (2011) Mutagenesis and computer modeling studies of a GPCR conserved residue W5.43(194) in ligand recognition and signal transduction for CB2 receptor. Int Immunopharmacol 11:1303-1310.

Zoja C, Locatelli M, Corna D, Villa S, Rottoli D, Nava V, Verde R, Piscitelli F, Di Marzo V, Fingerle J, et al. (2016) Therapy with a selective cannabinoid receptor type 2 agonist limits albuminuria and renal injury in mice with type 2 diabetic nephropathy. Nephron 132:59-69.

Address correspondence to: Dr. Frank Park, Department of Pharmaceutical Sciences, College of Pharmacy, University of Tennessee Health Science Center, 881 Madison Ave., Room 442, Memphis, TN 38163. E-mail: fpark@ uthsc.edu; or Dr. Bob M. Moore, Jr., Department of Pharmaceutical Sciences, College of Pharmacy, The University of Tennessee Health Science Center, 881 Madison Ave., Room 442, Memphis, TN 38163. E-mail: bmoore@uthsc.edu 